\title{
The Burden of Sarcoidosis Symptoms from a Patient Perspective
}

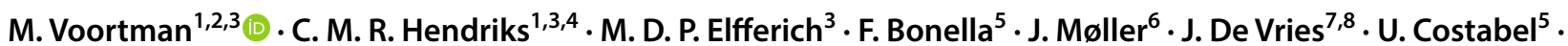 \\ M. Drent ${ }^{1,3,9}$
}

Received: 26 October 2018 / Accepted: 7 February 2019 / Published online: 16 February 2019

(C) The Author(s) 2019, corrected publication 2019

\begin{abstract}
Purpose The clinical manifestations of sarcoidosis vary widely, depending on the intensity of the inflammation and the organ systems affected. Hence, sarcoidosis patients may suffer from a great variety of symptoms. The aim of this study was to compare the self-reported burden of sarcoidosis patients in Denmark, Germany and the Netherlands, especially the prevalence of fatigue and small fiber neuropathy (SFN)-related symptoms, as well as differences in treatment strategies.

Methods A cross-sectional web-based anonymous survey about complaints was conducted among sarcoidosis patients. Patients were invited to take part through the sarcoidosis patient societies as well as through outpatient sarcoidosis clinics in these countries.

Results The questionnaire was completed by 1072 sarcoidosis patients (152 Danish, 532 German and 388 Dutch). Almost all patients reported having sarcoidosis-associated symptoms (organ-related as well as non-specific, non-organ related). Fatigue was reported by almost all respondents $(90 \%)$, followed by pulmonary symptoms $(72.4 \%)$. More than $50 \%$ of the respondents were being treated with prednisone, which was comparable in all three countries. In contrast, second- and thirdline treatment differed substantially between Denmark, Germany and the Netherlands.

Conclusion Sarcoidosis patients in Denmark, Germany and the Netherlands present with similar self-reported symptoms, organ-related as well as non-specific, non-organ related. Fatigue (90\%) and symptoms associated with SFN (86\%) were highly prevalent in all three countries.
\end{abstract}

Keywords Fatigue $\cdot$ Fatigue Assessment Scale (FAS) · Sarcoidosis · Sarcoidosis-associated symptoms · Small fiber neuropathy (SFN) · Small fiber neuropathy screenings list (SFNSL)

Electronic supplementary material The online version of this article (https://doi.org/10.1007/s00408-019-00206-7) contains supplementary material, which is available to authorized users.

M. Voortman

m.voortman@antoniusziekenhuis.nl

1 ILD Center of Excellence, Department of Pulmonology, St. Antonius Hospital, PO Box 2400, 3430 VB Nieuwegein, The Netherlands

2 Department of Pulmonology, Division of Heart \& Lungs, University Medical Centre Utrecht, Utrecht, The Netherlands

3 ILD Care Foundation Research Team, Ede, The Netherlands

4 Faculty of Medicine, Utrecht University, Utrecht, The Netherlands

\section{Introduction}

Sarcoidosis occurs throughout the world, affecting all races and ages. Its true prevalence remains unknown. To date, studies based on nationwide registries of demographic factors and diagnoses are relatively old and scarce [1-4]. Moreover, the epidemiological assessment of sarcoidosis and its

5 Interstitial and Rare Lung Disease Unit, Ruhrlandklinik, University Hospital, Essen, Germany

6 Department of Respiratory Diseases and Allergology, Aarhus University Hospital, Aarhus, Denmark

7 Department of Medical Psychology, Elisabeth-TweeSteden Hospital Tilburg, Tilburg, The Netherlands

8 Department of Medical and Clinical Psychology, Tilburg University, Tilburg, The Netherlands

9 Department of Pharmacology and Toxicology, FHML, Maastricht University, Maastricht, The Netherlands 
manifestations is problematic due to lack of consistent case definition, lack of sensitivity and specificity of diagnostic tests, variable diagnostic intensity and variable diagnostic methods [5].

The clinical manifestation, natural history and prognosis of sarcoidosis are highly variable, and its course is often unpredictable [6]. Depending on the organs involved and the severity of granulomatous inflammation, patients suffer from a broad range of symptoms. In addition to organrelated symptoms, patients often suffer from disabling nonspecific, non-organ-related symptoms [7-9]. Fatigue is the most frequently reported non-specific burdensome symptom in sarcoidosis patients, with a prevalence ranging from 50 to $90 \%$ [10, 11]. Other non-specific symptoms accounting for an important impact on the quality of life (QoL) of both patients and partners are small fiber neuropathy (SFN)related symptoms and everyday cognitive failure, including concentration problems, memory loss and decreased perception [7, 12-15]. Moreover, clinicians tend to have more attention for physical parameters than psychological issues in patients with sarcoidosis. To date, drugs used to treat severe organ involvement in sarcoidosis generally do not influence these non-specific symptoms and tend to cause side effects which then further increase the burden of disease.

The importance of patients' participation in healthcare has been increasingly acknowledged. Moreover, studies from a patients' perspective are important. Patients reported they regularly feel misunderstood and would like more attention and support for their problems [13]. Therefore, the aim of this study was to assess the self-reported burden of patients with sarcoidosis in three European countries, viz. Denmark, Germany and the Netherlands, especially regarding the prevalence of fatigue and SFN-related symptoms, as well as differences in treatment strategies.

\section{Materials and Methods}

\section{Study Design}

In cooperation with the Dutch Sarcoidosis Society, the ild care foundation has designed a questionnaire to assess complaints (organ-related as well as non-specific, nonorgan related) among patients with sarcoidosis. This crosssectional web-based anonymous survey was conducted from October 2017 to April 2018 among a sample of sarcoidosis patients in the Netherlands, and from December 2017 to August 2018 among samples of sarcoidosis patients in Denmark and Germany. The recruitment procedure aimed to compose representative samples of sarcoidosis patients in these countries.
This study was performed in accordance with the Declaration of Helsinki and its amendments. The Medical Ethics Committee of the St. Antonius Hospital Nieuwegein, the Netherlands, decided that, under the Dutch act on medical research involving human subjects, approval of this study by a Medical Ethics Committee was not necessary.

\section{Study Subjects and Procedure}

The overall study sample comprised sarcoidosis patients who were members of the Dutch Sarcoidosis Society (total number of patient members about 2000) and the Deutsche Sarkoidose Vereinigung (total number of patients members about 4000), and mainly from a sarcoidosis clinic in Denmark. Patients were recruited without incentives, since the survey was anonymous.

The survey was developed using the online questionnaire tool Surveymonkey (http://www.surveymonkey.com). The survey concerns the burden of disease and symptoms as experienced by patients with sarcoidosis. Further questions concerned demographics (gender, age, duration of sarcoidosis), use of medication and two sets of questionnaires validated for sarcoidosis, the Small Fiber Neuropathy Screening List (SFNSL) [16] and the Fatigue Assessment Scale (FAS) [17]. Patients were provided with a link to the electronic survey.

\section{Questionnaires}

The FAS is a 10-item self-report fatigue questionnaire. The response scale is a five-point scale ( 1 never to 5 always); scores on the FAS can range from 10 to 50. A score $>22$ indicates fatigue, and a score $>34$ indicates extreme fatigue. The reliability and validity of the FAS have been shown to be good in sarcoidosis patients [17]. So far, the FAS is available in 20 languages [18] (see Supplement 1and http://www. wasog.org/education-research/questionnaires.html).

The SFNSL is a 21-item self-administered questionnaire to screen for symptoms related to SFN. The response scale is a five-point scale ( 0 never to 4 always); scores on the SFNSL can range from 0 to 84 . The cutoff score of the SFNSL is 11: a score below 11 indicates no or few symptoms related to SFN, while a score of 11-48 indicates probable or highly probable SFN and a score above 48 is indicative of SFN [16]. The SFNSL is available in six languages: Danish, Dutch, English, French, German and Japanese (see Supplement 1 and http://www.wasog.org/education-research/quest ionnaires.html).

\section{Statistical Analysis}

All statistical analyses were performed using SPSS version 24 for Mac. Standard descriptive statistics were computed. 
ANOVA was used for comparison between the sarcoidosis samples in the three countries. In view of the large number of variables examined, a probability value of less than 0.01 was considered to be statistically significant.

\section{Results}

The characteristics of the samples studied are summarized in Table 1. A total of 1072 sarcoidosis patients [152 (68\% female) Danish; 532 (62\% female) German and 388 (53\% female) Dutch] completed the survey. The mean age was 51.8 years and did not differ between the three countries.

Self-reported pulmonary involvement was the most common complaint (72.4\%), followed by musculoskeletal involvement $(70.2 \%)$. Rates of musculoskeletal, cardiac and liver sarcoidosis differed between the three European countries.

Almost all patients (95\%) reported having symptoms (organ-related as well as non-specific, non-organ related). Of the non-specific, non-organ-related symptoms, fatigue was reported by almost all sarcoidosis patients in all three countries (approximately 90\%). SFN-related symptoms (86.2\%), reduced energy levels (80.6\%) and concentration (54.0\%), memory $(51 \%)$ and sleeping $(50.5 \%)$ problems were also often reported. None of these symptoms varied between the three European countries. Only memory problems tended to be more prevalent in Denmark (58.1\%, $p=0.05)$. Significant differences were found regarding self-reported pain, which was least prevalent in the Netherlands $(p \leq 0.001)$, and low vitamin D levels, with the highest prevalence in Germany $(31.7 \%, p=0.002)$.

More than $50 \%$ of the studied sample were being treated with prednisone, a rate which was comparable in all three countries. However, substantial differences were found concerning second- and third-line treatment. Methotrexate (MTX) was used more commonly in Denmark and the Netherlands than in Germany [23.5\% (DN) and 21.7\% (NL) vs. $8.5 \% ; p \leq 0.001]$, while azathioprine (AZA) was prescribed more often in Germany [9.2\% vs. $7.4 \%$ (DN) and $3.8 \%$ (NL); $p \leq 0.001]$. TNF-alpha inhibitors were used most frequently in the Netherlands [ $7.2 \%$ vs. $4.0 \%(\mathrm{DN})$ and $2.6 \%$ (GE); $p \leq 0.001]$. In total, $34.9 \%$ of the patients in Denmark, $32.7 \%$ of the patients in the Netherlands and $20.3 \%$ of the patients in Germany were receiving second- or third-line treatments. The use of calcium supplementation was higher in Denmark [38.0\% (DN) vs. 10.5\% (GE) and 10.0\% (NL); $p \leq 0.001$, and more German patients reported using pain killers (including opioids).

Based on the assumption that an FAS score above 22 indicates fatigue, approximately $90 \%$ of the sarcoidosis patients in all three countries were affected by fatigue. The mean FAS score in the three European countries was 32.1 (the highest score being found in the Netherlands: 33.1; $p \leq 0.001$; see Table 2). Patients in the Netherlands and Denmark reported more extreme fatigue (FAS $>34$ ) than those in Germany [47.9\% (NL) and 46.3\% (DN) vs. 33.7\% (GE); $p \leq 0.001$ ] (see also Fig. 1).

Based on the assumption that an SFNSL score $>11$ indicates probable or highly probable SFN, $>80 \%$ of the sarcoidosis patients in all three countries are affected by SFN-related symptoms. The mean SFNSL score in the three European countries was 29 (the highest score being found in Denmark: $32.4 ; p \leq 0.004)$. The highest prevalence of SFN-related symptoms was seen in Denmark (91.9\%), followed by Germany (84.6\%). In the Netherlands, $82.2 \%$ of the patients reported SFN-related symptoms (see also Table 2). The prevalence of scores $>48$ (indicative of SFN) was also substantial: $18.5 \%$ in Denmark, $12.3 \%$ in Germany and $15.5 \%$ in the Netherlands (see also Fig. 2).

\section{Discussion}

Our findings demonstrate that the self-reported burden of sarcoidosis is high. Almost all patients reported sarcoidosis-associated symptoms (organ-related as well as nonspecific, non-organ related). Of the non-specific symptoms, fatigue (assessed by the FAS) and reduced energy levels were reported by almost all sarcoidosis patients in the three European countries we studied (approximately 90 and $80 \%$, respectively). In addition, over $80 \%$ of the respondents reported SFN-related symptoms (as assessed by the SFNSL). Pulmonary involvement was the most frequently organ-related manifestation reported, followed by musculoskeletal manifestations.

Difficulties arise when estimating the real extent and prevalence of organ involvement and non-specific symptoms associated with sarcoidosis in a community. Descriptions differ widely among populations in the world and even between various regions within countries, as standardization of the diagnostic criteria is still lacking [1]. To date, epidemiological data on the prevalence of various manifestations in the European countries we studied are sparse. In Denmark, $50 \%$ of the cases in a National Patient Registry were apparently asymptomatic [1]. New imaging tests such as PET scans, revealing occult sarcoidosis localizations and/or multiple organ involvement, have led to changes in reported manifestations [5, 19]. In the present study, the reported proportion of organ involvement was comparable between the three countries, except for cardiac and liver involvement (both most prevalent in Germany).

Clinically apparent cardiac involvement has been noted in $2-10 \%$ of patients [20], while the prevalence of clinically silent cardiac sarcoidosis is much higher. Advanced imaging, including PET scans and magnetic resonance imaging 
Table 1 Summary of the characteristics of the sarcoidosis patient samples from Denmark, Germany and the Netherlands

\begin{tabular}{|c|c|c|c|c|}
\hline & Denmark & Germany & The Netherlands & p value $\mathrm{e}^{\#}$ \\
\hline Number & 152 & 532 & 388 & \\
\hline Gender, male (\%) & 31.9 & 38.0 & 46.6 & $<0.001$ \\
\hline Age, years, mean $\pm \mathrm{SD}$ (range) & $52.1 \pm 9.9(12-72)$ & $52.3 \pm 9.2(23-80)$ & $51.1 \pm 9.7(24-75)$ & NS \\
\hline \multicolumn{5}{|l|}{ Organ involvement (\%) } \\
\hline Pulmonary & 75.0 & 73.0 & 69.1 & NS \\
\hline Cardiac & 2.1 & 7.8 & 5.4 & $<0.001$ \\
\hline Musculoskeletal & 80.9 & 69.3 & 60.5 & $<0.001$ \\
\hline Skin & 31.6 & 35.8 & 27.3 & NS \\
\hline Low vitamin $\mathrm{D}$ & 27.9 & 31.7 & 20.4 & 0.002 \\
\hline Hypercalcemia & 9.6 & 4.5 & 6.7 & NS \\
\hline Nervous system & 10.3 & 11.9 & 11.6 & NS \\
\hline Liver & 4.4 & 14.8 & 6.7 & $<0.001$ \\
\hline \multicolumn{5}{|l|}{ Symptoms (\%) } \\
\hline None & 4.4 & 4.7 & 1.5 & NS \\
\hline Organ-related symptoms (\%) & 95.6 & 95.3 & 95.9 & NS \\
\hline \multicolumn{5}{|l|}{ Pulmonary } \\
\hline Dyspnoea & 65.4 & 62.3 & 61.1 & NS \\
\hline Cough & 49.3 & 42.1 & 38.1 & 0.05 \\
\hline Extrapulmonary & 95.6 & 94.6 & 90.7 & NS \\
\hline Cardiac arrhythmia* & 14.7 & 18.7 & 28.4 & $<0.001$ \\
\hline Dizziness/fainting & 33.8 & 29.4 & 29.3 & $<0.001$ \\
\hline Kidney stones & 5.1 & 5.1 & 6.2 & NS \\
\hline Non-organ-related symptoms (\%) & 95.6 & 97.7 & 94.4 & NS \\
\hline Fatigue & 89.9 & 89.7 & 90.7 & NS \\
\hline Pain & 74.5 & 68.9 & 62.5 & $<0.001$ \\
\hline Reduced energy levels & 80.9 & 82.1 & 78.7 & NS \\
\hline Concentration problems & 51.5 & 54.2 & 56.2 & NS \\
\hline Memory problems & 58.1 & 46.9 & 47.9 & 0.05 \\
\hline Sleeping problems & 56.6 & 50.4 & 44.6 & NS \\
\hline Restless legs & 36.8 & 32.1 & 33.2 & NS \\
\hline Dry or running eyes & 43.4 & 42.6 & 39.7 & NS \\
\hline \multicolumn{5}{|l|}{ Medication (\%) } \\
\hline None, ever & 27.1 & 32.0 & 33.2 & NS \\
\hline Predniso(lo)n & 56.6 & 51.4 & 54.8 & NS \\
\hline Methotrexate & 23.5 & 8.5 & 21.7 & $<0.001$ \\
\hline Azathioprine & 7.4 & 9.2 & 3.8 & 0.01 \\
\hline Hydroxychloroquine & 5.9 & 0.1 & 4.9 & $<0.001$ \\
\hline Anti-TNF-alfa & 4.0 & 2.6 & 7.2 & $<0.001$ \\
\hline Vitamin D & 39.1 & 40.5 & 29.8 & $<0.001$ \\
\hline Calcium & 38.0 & 10.5 & 10.0 & $\begin{array}{l}\text { NS } \\
\text { (DN vs. GE } \\
\text { and DN vs. } \\
\text { NL }<0.001 \text { ) }\end{array}$ \\
\hline Pain killers or nsaids & 35.3 & 48.6 & 32.7 & 0.005 \\
\hline Sleeping medication & 5.9 & 4.3 & 8.5 & NS \\
\hline
\end{tabular}

$T N F$ tumor necrosis factor, $N S$ nonsignificant, $N S A I D$ non-steroidal anti-inflammatory drug; $D N$ Denmark, $G E$ Germany, $N L$ the Netherlands

*Patient's experience not confirmed by a cardiologist

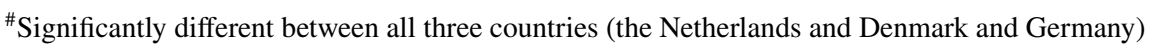


Table 2 Fatigue Assessment Scale (FAS) and small fiber neuropathy screening list (SFNSL) scores of the sarcoidosis samples from Denmark, Germany and the Netherlands

\begin{tabular}{|c|c|c|c|c|}
\hline & Denmark & Germany & $\begin{array}{l}\text { The Nether- } \\
\text { lands }\end{array}$ & $\mathrm{p}$ value \\
\hline FAS, total \pm SD & $32.3 \pm 8.4$ & $30.8 \pm 7.7$ & $33.1 \pm 8.1$ & $<0.001$ \\
\hline $\begin{array}{l}\text { FAS, men- } \\
\text { tal } \pm \text { SD }\end{array}$ & $14.6 \pm 4.6$ & $13.8 \pm 4.2$ & $15.0 \pm 4.4$ & $<0.001$ \\
\hline $\begin{array}{c}\text { FAS, physi- } \\
\text { cal } \pm \text { SD }\end{array}$ & $17.7 \pm 4.5$ & $17.4 \pm 9.1$ & $18.1 \pm 4.2$ & NS \\
\hline $\begin{array}{l}\text { SFNSL, } \\
\text { total } \pm \text { SD }\end{array}$ & $32.4 \pm 16.4$ & $26.6 \pm 17.8$ & $27.9 \pm 18.7$ & 0.004 \\
\hline
\end{tabular}

$S D$ standard deviation, $N S$ nonsignificant

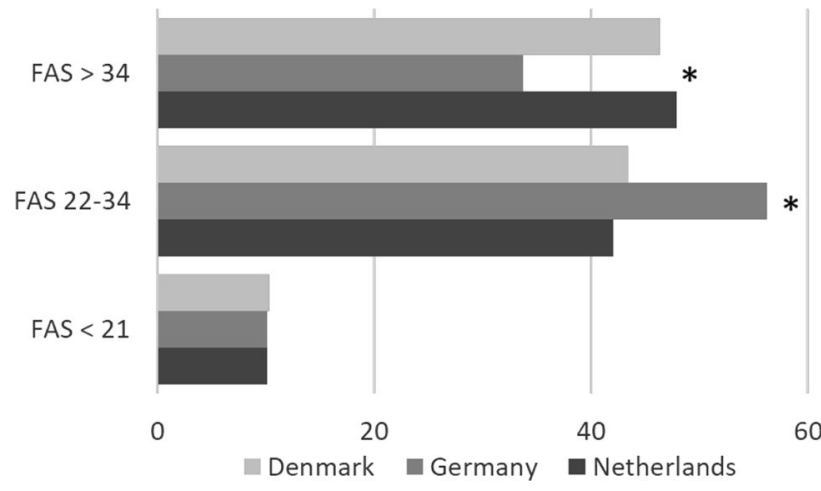

Fig. 1 Fatigue Assessment Scale (FAS) subscores per country. FAS scores below 22 indicate no fatigue, scores between 22 and 34 indicate mild to moderate fatigue, and scores above 34 indicate severe fatigue [18]. $*=$ p value $<0.001(\mathrm{GE}$ vs. $\mathrm{DN}+\mathrm{NL})$

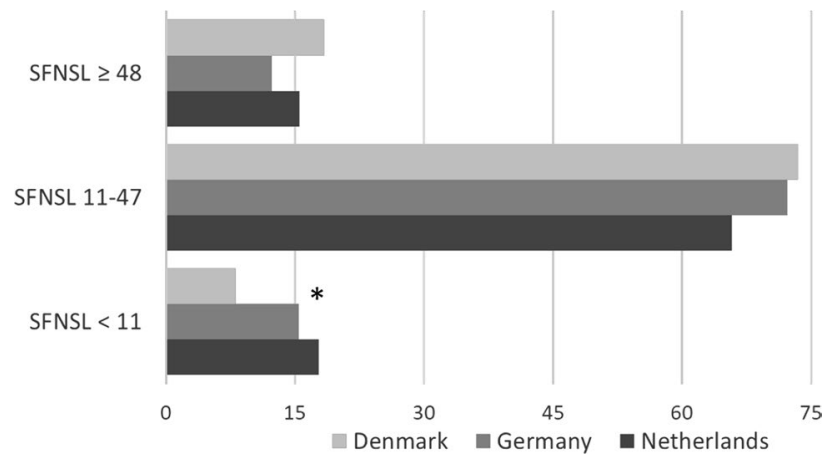

Fig. 2 Small Fiber Neuropathy Screening List (SFNSL) subscores per country. A score below 11 indicates few or no SFN-related symptoms, a score between 11 and 48 indicates probable or highly likely SFN, and a score above 48 is indicative of SFN [16] $*=p$ value $<0.001$ (DN vs. GE $+\mathrm{NL}$ )

(MRI), has improved the detection of cardiac sarcoidosis [20]. Apparently, there are differences in the presentation of sarcoidosis in this respect between patients from Europe and America and those from Japan, as Japanese studies have reported much higher rates of cardiac involvement. The prevalence of cardiac involvement reported in the present study was similar to previously reported rates (8\%) in large sarcoidosis samples in Germany [2, 21]. In contrast, the present study showed a rather lower prevalence in Denmark (2.1\%), which is not consistent with previously reported rates in Denmark (8.6\%) [22]. This difference may be due to the fact that our Danish study sample as well as the previous study was conducted in a single center [22]. Moreover, the prevalence of manifestations also depends on the available diagnostic procedures, the expertise of the clinicians and the definition used to determine organ involvement in various centers.

Liver problems in sarcoidosis could be associated with, at least partly, hepatic sarcoidosis, hepatotoxic medication such as azathioprine and/or alcohol intake. In line with the findings of the present study, Kirsten and Bosse-Henck et al. reported high rates of liver involvement (15\%) in large sarcoidosis samples in Germany [2, 21]. Recently, liver involvement was found in approximately $15 \%$ of a Dutch sarcoidosis sample, which is higher than reported in the present study (6.7\%) [23]. This can probably be explained by the fact that the sample studied by Cremers et al. included more chronic, advanced sarcoidosis patients, since their study was performed in a tertiary referral center. So far, comparative epidemiologic data on liver involvement in Denmark are lacking.

Organ-specific symptoms were comparable between the three countries, except for musculoskeletal symptoms (being most prevalent in Denmark). Musculoskeletal manifestations occur in approximately one-third of sarcoidosis patients [24]. Since they are often subclinical or not recognized because of mild or non-specific symptoms, however, their exact prevalence is unknown. The most frequent musculoskeletal manifestation of sarcoidosis is an acute arthritis that occurs as part of the Löfgren syndrome [24]. Higher rates of musculoskeletal involvement have been reported since the introduction of the PET-CT [25]. Awareness of organ involvement and sarcoidosis-associated symptoms will continue to increase with the improvement in diagnostic options and more prominent patient participation in the management of their disease.

In line with previous studies, the present study found that non-specific symptoms were frequently reported by sarcoidosis patients [9-11, 13, 14, 26, 27]. Hinz et al. reported fatigue in $70 \%$ of the German sarcoidosis population (mean FAS score: 26.3 [26]) and De Kleijn et al. reported fatigue in $83 \%$ of the Dutch sarcoidosis population (mean FAS score: 30.3 [28]). To date, ours was the first study evaluating fatigue in Denmark, so no previous data exist. These findings underline the clinical importance of assessing fatigue in sarcoidosis and integrating it in the multidisciplinary management of this disease. The etiology of sarcoidosis-associated 
fatigue is poorly understood and is likely to be multifactorial, encompassing active inflammation, cytokine release, depressive symptoms, sleep disturbance, anxiety, everyday cognitive failure and/or SFN-related symptoms [7, 11]. Fatigue can also be caused by systemic treatments for sarcoidosis, such as corticosteroids [29, 30]. Recently, our group demonstrated that predictors of fatigue include everyday cognitive failure, SFN-associated symptoms, depressive symptoms, anxiety, muscle pain and dyspnea [8]. Although our survey did not include a depressive symptoms inventory, it can be concluded from earlier studies by our group and others that the presence of depressive symptoms is one of the most important predictors of fatigue [8, 21]. Moreover, more than fifty percent of the patients in our sample reported memory and concentration problems, symptoms associated with cognitive failure and fatigue [8].

Ours was also the first study to assess SFN-related symptoms among sarcoidosis patients in Denmark and Germany. SFN-related symptoms, including pain, were frequently reported by all participants in the present study. In the follow-up of sarcoidosis patients, routine tests to assess disease activity do not measure pain, so the results of tests do not always correlate with the patients' well-being [4]. Since pain is a substantial problem in sarcoidosis, appropriate questionnaires to obtain information about pain might be helpful [9].

The percentage of patients using drugs was comparable in the three European countries (around 70\%). However, treatment strategies differed between these three countries, a difference which was largely caused by the difference in second- and third-line treatment [20\% (GE) vs. 33\% (NL) and 35\% (DN)]. Patients in Denmark and the Netherlands were more likely to use methotrexate and TNF-alpha inhibitors, whereas in Germany azathioprine was regarded as the treatment of first choice when prednisone alone was not effective. Remarkably, TNF-alpha inhibitors were prescribed most frequently in the Netherlands. This can most probably be explained by differences between the three countries in the health care insurance systems and/or local guidelines.

\section{Limitations}

One of the limitations of the present study was the patient recruitment method used in the three countries. The majority of the patients were recruited through patient societies. One could argue that it is only symptomatic patients who become members of a patients' society or are specifically referred to a specialized sarcoidosis clinic, and so these were more likely to take part in the survey than asymptomatic patients, causing selection bias and considerably influencing the rate of symptomatic cases in this study. Therefore, these results are only applicable to symptomatic patients. At present, the rate of symptoms in the unselected nationwide sarcoidosis population remains unknown. Another limitation is the fact that the symptoms were self-reported, which could lead to bias. However, the burden of sarcoidosis is determined by the experience of the patients themselves, and we barely saw any differences in prevalence rates of sarcoidosis-associated symptoms between the European countries we studied.

\section{Conclusion}

This study shows that sarcoidosis patients in Denmark (DN), Germany (GE) and the Netherlands (NL) report similar sarcoidosis-associated symptoms, including organ-related as well as non-specific, non-organ-related symptoms. Fatigue (90\%) and symptoms associated with SFN (mean 86\%: DN $91.9 \%$, GE $84.6 \%$ and NL $82.2 \%$, respectively) were highly prevalent in all three countries.

Beside better disease education, psychological support is warranted. The combined use of appropriate questionnaires, lung function tests, imaging procedures and other clinical assessments of disease activity and severity provides a framework for evaluating organ-related as well as nonorgan-related symptoms.

In view of the broad range of possible symptoms, sarcoidosis patients may consult various doctors, so the management of sarcoidosis patients should use a multidisciplinary approach that focuses on somatic as well as psychosocial aspects of this erratic disorder. Furthermore, as treatment strategies differ in the three European countries we studied, updated international sarcoidosis treatment guidelines are urgently needed.

Acknowledgements We would like to thank Rob van Jaarsveld, board member of the Dutch Sarcoidosis Society (Sarcoidose.nl) and Bernd Quadder of the Deutsche Sarkoidose Vereinigung for their excellent translation, distribution and/or promotion of the survey. Also, we would like to thank the Danish Pulmonary Society for the promotion of the survey.

Funding This study was supported by a research grant from the ild care foundation: http://www.ildcare.nl. M.V. is supported by a research Grant from the Netherlands Organization for Health Research and Development, ZonMw (Project Number 842002005). The study sponsors had no involvement in the study design, in the collection, analysis, and interpretation of data, in the writing of the manuscript or in the decision to submit the manuscript for publication.

\section{Compliance with Ethical Standards}

Conflict of interest On behalf of all authors, the corresponding author states that there is no conflict of interest.

Open Access This article is distributed under the terms of the Creative Commons Attribution 4.0 International License (http://creativeco mmons.org/licenses/by/4.0/), which permits unrestricted use, distribution, and reproduction in any medium, provided you give appropriate credit to the original author(s) and the source, provide a link to the Creative Commons license, and indicate if changes were made. 


\section{References}

1. Byg KE, Milman N, Hansen S (2003) Sarcoidosis in Denmark 1980-1994. A registry-based incidence study comprising 5536 patients. Sarcoidosis Vasc Diffuse Lung Dis 20(1):46-52

2. Kirsten D (1995) Sarcoidosis in Germany. Analysis of a questionnaire survey in 1992 of patients of the German Sarcoidosis Group. Pneumologie 49(6):378-382

3. Valeyre D, Prasse A, Nunes H, Uzunhan Y, Brillet PY, MullerQuernheim J (2014) Sarcoidosis. Lancet 383(9923):1155-1167. https://doi.org/10.1016/S0140-6736(13)60680-7

4. Wirnsberger RM, de Vries J, Breteler MH, van Heck GL, Wouters EF, Drent M (1998) Evaluation of quality of life in sarcoidosis patients. Respir Med 92(5):750-756

5. Gerke AK, Judson MA, Cozier YC, Culver DA, Koth LL (2017) Disease burden and variability in sarcoidosis. Ann Am Thorac Soc 14(Supplement_6):S421-S428. https://doi.org/10.1513/Annal sATS.201707-564OT

6. Statement on sarcoidosis. Joint Statement of the American Thoracic Society (ATS), the European Respiratory Society (ERS) and the World Association of Sarcoidosis and Other Granulomatous Disorders (WASOG) adopted by the ATS Board of Directors and by the ERS Executive Committee, February 1999 (1999). Am J Respir Crit Care Med 160 (2):736-755. https://doi.org/10.1164/ ajrccm.160.2.ats4-99

7. Drent M, Strookappe B, Hoitsma E, De Vries J (2015) Consequences of sarcoidosis. Clin Chest Med 36(4):727-737. https:// doi.org/10.1016/j.ccm.2015.08.013

8. Hendriks C, Drent M, De Kleijn W, Elfferich M, Wijnen P, De Vries J (2018) Everyday cognitive failure and depressive symptoms predict fatigue in sarcoidosis: a prospective followup study. Respir Med 138S:S24-S30. https://doi.org/10.1016/j. rmed.2017.11.008

9. Hoitsma E, De Vries J, van Santen-Hoeufft M, Faber CG, Drent M (2003) Impact of pain in a Dutch sarcoidosis patient population. Sarcoidosis Vasc Diffuse Lung Dis 20(1):33-39

10. Marcellis RG, Lenssen AF, Elfferich MD, De Vries J, Kassim S, Foerster K, Drent M (2011) Exercise capacity, muscle strength and fatigue in sarcoidosis. Eur Respir J 38(3):628-634. https:// doi.org/10.1183/09031936.00117710

11. Drent M, Lower EE, De Vries J (2012) Sarcoidosis-associated fatigue. Eur Respir J 40(1):255-263. https://doi. org/10.1183/09031936.00002512

12. Bakkers M, Faber CG, Hoeijmakers JG, Lauria G, Merkies IS (2014) Small fibers, large impact: quality of life in small-fiber neuropathy. Muscle Nerve 49(3):329-336. https://doi.org/10.1002/ mus. 23910

13. Moor CC, van Manen MJG, van Hagen PM, Miedema JR, van den Toorn LM, Gur-Demirel Y, Berendse APC, van Laar JAM, Wijsenbeek MS (2018) Needs, perceptions and education in sarcoidosis: a live interactive survey of patients and partners. Lung 196(5):569-575. https://doi.org/10.1007/s00408-018-0144-4

14. Voortman M, Fritz D, Vogels OJM, Eftimov F, van de Beek D, Brouwer MC, Drent M (2017) Small fiber neuropathy: a disabling and underrecognized syndrome. Curr Opin Pulm Med 23(5):447457. https://doi.org/10.1097/MCP.0000000000000413

15. Elfferich MD, Nelemans PJ, Ponds RW, De Vries J, Wijnen PA, Drent M (2010) Everyday cognitive failure in sarcoidosis: the prevalence and the effect of anti-TNF-alpha treatment. Respiration 80(3):212-219. https://doi.org/10.1159/000314225

16. Hoitsma E, De Vries J, Drent M (2011) The small fiber neuropathy screening list: Construction and cross-validation in sarcoidosis. Respir Med 105(1):95-100. https://doi.org/10.1016/j. rmed.2010.09.014

17. De Vries J, Michielsen H, Van Heck GL, Drent M (2004) Measuring fatigue in sarcoidosis: the Fatigue Assessment Scale (FAS). Br J Health Psychol 9(Pt 3):279-291. https://doi.org/10.1348/13591 07041557048

18. Hendriks C, Drent M, Elfferich M, De Vries J (2018) The Fatigue Assessment Scale: quality and availability in sarcoidosis and other diseases. Curr Opin Pulm Med 24(5):495-503. https://doi. org/10.1097/MCP.0000000000000496

19. Ganeshan D, Menias CO, Lubner MG, Pickhardt PJ, Sandrasegaran K, Bhalla S (2018) Sarcoidosis from head to toe: what the radiologist needs to know. Radiographics 38(4):1180-1200. https ://doi.org/10.1148/rg.2018170157

20. Bakker AL, Grutters JC, Keijsers RG, Post MC (2017) Cardiac sarcoidosis: challenges in clinical practice. Curr Opin Pulm Med 23(5):468-475. https://doi.org/10.1097/MCP.0000000000000410

21. Bosse-Henck A, Koch R, Wirtz H, Hinz A (2017) Fatigue and excessive daytime sleepiness in sarcoidosis: prevalence, predictors, and relationships between the two symptoms. Respiration 94(2):186-197. https://doi.org/10.1159/000477352

22. Ghanizada M, Rossing K, Bundgaard H, Gustafsson F (2018) Clinical presentation, management and prognosis of patients with cardiac sarcoidosis. Dan Med J 65 (4)

23. Cremers J, Drent M, Driessen A, Nieman F, Wijnen P, Baughman R, Koek G (2012) Liver-test abnormalities in sarcoidosis. Eur J Gastroenterol Hepatol 24(1):17-24. https://doi.org/10.1097/ MEG.0b013e32834c7b71

24. Bechman K, Christidis D, Walsh S, Birring SS, Galloway J (2018) A review of the musculoskeletal manifestations of sarcoidosis. Rheumatology 57(5):777-783. https://doi.org/10.1093/rheum atology/kex317

25. Mostard RL, Prompers L, Weijers RE, van Kroonenburgh MJ, Wijnen PA, Geusens PP, Drent M (2012) F-18 FDG PET/CT for detecting bone and bone marrow involvement in sarcoidosis patients. Clin Nucl Med 37(1):21-25. https://doi.org/10.1097/ RLU.0b013e3182335f9b

26. Hinz A, Fleischer M, Brahler E, Wirtz H, Bosse-Henck A (2011) Fatigue in patients with sarcoidosis, compared with the general population. Gen Hosp Psychiatry 33(5):462-468. https://doi. org/10.1016/j.genhosppsych.2011.05.009

27. Korenromp IHE, Heijnen CJ, Vogels OJM, van den Bosch JMM, Grutters JC (2011) Characterization of chronic fatigue in patients with sarcoidosis in clinical remission. Chest 140(2):441-447. https://doi.org/10.1378/chest.10-2629

28. de Kleijn WP, Elfferich MD, De Vries J, Jonker GJ, Lower EE, Baughman RP, King TE Jr, Drent M (2009) Fatigue in sarcoidosis: American versus Dutch patients. Sarcoidosis Vasc Diffuse Lung Dis 26(2):92-97

29. Fleischer M, Hinz A, Brahler E, Wirtz H, Bosse-Henck A (2014) Factors associated with fatigue in sarcoidosis. Respir Care 59(7):1086-1094. https://doi.org/10.4187/respcare.02080

30. Judson MA, Chaudhry H, Louis A, Lee K, Yucel R (2015) The effect of corticosteroids on quality of life in a sarcoidosis clinic: the results of a propensity analysis. Respir Med 109(4):526-531. https://doi.org/10.1016/j.rmed.2015.01.019

Publisher's Note Springer Nature remains neutral with regard to jurisdictional claims in published maps and institutional affiliations. 